\title{
Normality and Pathology in a Biological Age
}

\begin{abstract}
Summary
The article is the text of a lecture given at the Faculty of the Humanities, March 2001. It argues that one implication of recent advances in the sciences of life may be that the binary opposition of the normal and the pathological is put into question. Canguilheim's distinction between vital and social norms is challenged and superseded by a Foucauldian genealogical approach to programs for the government of individuals, and the norms of life that emerged in the nineteenth and twentieth centuries are argued to be fundamentally social. Viewing genetics, biopsychiatry, and the commercialisation of drug development and biomedicine, the author argues that the logic of normalisation is loosing its hold, and being replaced by strategies for the continuous molecular management of variation, the modulation of susceptibilities, and the capitalisation of life itself.
\end{abstract}

\section{Introduction}

$\mathrm{S}$ ince about the middle of the nineteenth century, our ways of governing human conduct have been structured by the division between the normal and the abnormal - by the idea of norm and deviation. Across the twentieth century, the norm was medicalised, statisticalised, moralised and socialised - to be normal was to be healthy, to be average, to be virtuous and to be socially acceptable. A host of professions came to organise their thoughts, calculations and judgements in terms of the binary of the normal and the pathological, and to conceive of their interventions in terms of a project of normalisation. So, as we enter the 21 st century, are we still governed by the logic of the norm? And what are the implications of recent advances in the sciences of life - from the decoding of the human genome to the new neuroscientific knowledges of the brain and its mechanisms - and of the linked developments in the technologies of treatment - from the cloning of stem cells to psychopharmacology?

I am writing these words on the very day when the first 'map' of the human genome is published on the internet - the 11th February 2001. As you will all know by now, this produced at least one major surprise - there were too few genes! Rather than the 100,000 or so genes that had been confidently predicted, there seem to be only around 31,000 sequences coding for chains of amino acids - which compares with 6,000 for a yeast cell, 13,000 for a fruit fly, 20,000 for a nematode worm and 26,000 for an average plant. So where are all those genes that account for our vast behavioural repertoire, for our consciousness, for our physical co-ordination, for learning and memory? This doesn't seem to be a 'parts list' to make a human - 
even a modern jet aeroplane contains more than 200,000 unique parts. The predictions and anxieties about 'the gene for' everything from homosexuality to a sense of humour both those of the gene hunters and those of their sociological critics - seem to have been confounded. Craig Venter of Celera Genomics, who hoped to be the legal owner of the human genome, pronounced "The notion that one gene equals one disease, or that one gene produces one protein, is flying out of the window". ${ }^{1}$ The project is regrouping around the genes that control genes, or around the interactions between genes. Or perhaps, as theologians rush to suggest, in the space between the paucity of genes and the richness of human existence and creativity lies a space for god, a space for the soul: as Paul Rabinow has shown in French DNA, the French have been hard at work for some time to produce the spiritual in this genomic domain (Rabinow, 1999).

The very idea of what it is to be human is being reshaped by these new knowledges and techniques of human individuality. But this is not taking the form that critics had predicted. In genomics, the information paradigm - code of codes, book of life, digital instructions and the like - has been thrown into doubt as the genome itself seems to be full of all sorts of relics of the past, introjected sequences from bacteria, strange and apparently functionless duplications, sequences long deactivated. The human genome seems more like an assemblage put together over millennia by squabbling tribes of mad bricoleurs than a digital programme written by the harsh logic of natural selection, and survival of the selfish gene. Something postgenomics - is taking shape. And in other areas too, the reshaping of personhood brought about by new life sciences is not taking the essentialist, reductionist, determinist

1 Quoted in the British Medical Journal, 2001, 322: 381. form that many had anticipated. Histories of the present turn out to be easier to write than fictions of the future. But perhaps we can attempt some diagnoses, not to predict the future or even to describe the present, but to find the lines of truth and power within which the new human beings of the biological age are coming into existence.

\section{Norms}

T et me start with norms. As is well know, the French historian and philosopher of the life sciences, Georges Canguilhem (1978) argued that there was a fundamental distinction between two types of norms - vital norms and social norms. In On The Normal and the Pathological, he asserted that life was itself a vital and normative process. Vital norms arose from the very nature of living beings and the constant work of adaptation that they try to do in order to resist death. The vital norms of the living being are not merely human judgements or statistical averages across a population. Vital normativity, in the life sciences and medicine, arose from the specific character of their object - of living beings. He writes "It is life itself, and not medical judgement that makes the biological normal a concept of value and not a concept of statistical reality." (ibid., 43). Health, for the living organism, is not just normality but normativity - the vital force that resists disease. Pathology was a reduction of this vital normativity - illness was fixity, inability to adapt, stasis. Life was organic, systematic, self regulating - hence the importance of disease for knowledge: "Disease reveals normal functions to us at the precise moment when it deprives us of their existence... Health is organic innocence. It must be lost, like all innocence, so that knowledge may be possible... the truly vital wonder is the anguish caused by disease." (ibid., 52) 
But Canguilhem thought that social norms were very different. Social norms manifest only adaptation to a particular artificial order of society. They arise from the requirements of those in power for normativity, docility, productivity, harmony and the like. In a widely quoted passage, he remarks that "Between 1759, when the word 'normal' appeared, and 1834 when the word 'normalised' appeared, a normative class had won the power to identify - a beautiful example of ideological illusion - the function of social norms, whose content it determined, with the use that that class made of them" (ibid., 151). The norms of the economy, of the school, of the legal system and so forth thus arose from judgements of desirability made by groups with particular interests. And the most intense problems arise where one set of norms are read in terms of the other - when social norms were treated as if they were vital, and arose from the nature of the human being, rather than from a contingent social judgement of personhood. The critical slogans of much social science echo this view - essentialism, reductionism, determinism, geneticisation - each suggests that a social judgement of deviation from desirability is taken to be a vital pathology.

From this perspective, it is tempting to suggest that the new politics of life have once more mistaken social norms of personhood for vital ones. Thus we could argue that a social norm of health has replaced a vital one - health as eternal youth, as physical perfection, as ever prolonged life expectancy, as fertility for all and at any age and so forth. And, in relation to the mind, one could argue that it is a social norm of happiness, contentment and adjustment, for example, that underlies contemporary psychiatry. In its new guise - psycho-pharmacology - it seems to have taken key features of vitality itself as abnormalities open to normalisation. Sadness becomes treatable depression, dis- like of social situations becomes treatable social phobia - in the name of a social, not a vital, norm of health. I'll return to these examples later.

For Michel Foucault, Canguilhem's pupil, however, it was not only social norms that had a history - vital norms were historical too. Foucault argued that the very idea of the norm took shape within programmes for the government of individual and collective existence in nineteenth century Europe. These programmes gridded the space and time of existence with standards of conduct of dress, manners, punctuality, conduct, performance. This enabled judgements of deviation to be made in the schools, factories, army, hospital, reformatory, and processes of normalisation to be set in motion. And these norms were linked up with those of medicine, they were naturalised. Take nineteenth century psychiatry. On the one hand, it collected a whole array of undesirable forms of conduct within its mandate - public disorder, promiscuity, dangerousness, inebriety - a vast expansion of the symptomatic field. And, on the other hand, via the link with medicine, it brought these violations of norms of conduct into relation with the idea of abnormalities in the healthy functioning of bodily processes. Norms of conduct get understood in terms of the binary of health and morbidity. From now on, psychiatry will deal with a medico-judicial field in which these two sorts of norms are inextricably mixed.

But vital norms themselves could only arise within specific apparatuses for the government of health. One such apparatus was the enclosed institutional space of the hospital. Large numbers of sick people were observed, their details were recorded, as they were citizens after all. Their symptoms were observed and written down in case notes. Their prognosis was followed. And after they were dead, their corpses were opened up by 
dissection, and the organic seat of their sad decline was revealed to the medical gaze. Vital norms arose only when the individual gaze of the doctor or the anatomist could be statisticalised in these 'machines for cure'. But vital norms were social too: as Foucault was fond of pointing out, medicine was the first 'social' science. The norms of longevity, morbidity, reproduction and so forth arose in projects for the government of collective health and sickness. They were mapped out through statistics of birth, death, rates and types of morbidity. They emerged in practices ranging from sewage systems to insurance that regulated the population in the name of health. All these processes - let us call them biopolitics - were conditions for the emergence of the notion of the idea of the vital normativity of the living human being and the human population.

So my point is that social and vital norms of individuals and populations have always been inextricably intertwined at the very heart of medical knowledge. Such norms were developed further in the programmes of social welfare and national health that took shape across the twentieth century. It was in the universal and compulsory practices of schooling that the idea of 'normal development' in the child was formed, including normal physical development, and all the techniques of weighing, measuring, assessing were invented: they solidified the idea that there were biological norms of height, weight and development and that deviations were biomedical abnormalities - slow development, obesity and so forth. Our norms of procreation, which radically changed the vital lives of women, emerged within domestication of sexuality and reproduction in the family. Our beliefs about which human ills were normal and which were treatable arose from the transformation of the home into a machine for creating and maintaining hygiene. Norms of the labouring body arose from the penetration of the gaze of welfare medicine into the workplace, which also gave us the apparently natural life course the times when one was too young to labour, the times of labour, and the times of retirement. And so forth.

These norms and judgements still shape much medical thought and practice. But contemporary ideas of health and life do not arise out of these zones that have been gridded by government. New forces are judging vitality in relation to different objectives. There are the commercial organisations such as the pharmaceutical companies whose interests are the bottom line - profit. There are professionals ranging from doctors to research scientists where humanistic aspirations are linked to mundane concerns for fame, fortune and career, advancement in their careers, fame and fortune. There are insurance companies with their criteria for benefits and so forth. There are medical institutions with their decisions as to whom to treat, at what ages for what conditions, under what criteria - for example, should there be 'treatment' for infertility, or plastic surgery for children with Downs' syndrome - decisions that are simultaneously concerned with efficacy, equity and economy. There are philanthropic bodies, such as NGOs, charities, pressure groups and campaigning organisations who now play a key role in demanding the rights to health, and to treatment for all manner of conditions and persons. And, of course, the subjects and patients themselves now play a key role in shaping our judgements as to what is 'a suitable case for treatment'.

In this new configuration we have examinations galore, but they do not seem to operate in terms of hierarchical observation, distribution of individuals according to their qualities, and normalising judgement against institutional expectations. There are plenty of charts of normal functioning, and graphs 
of distributions, but these do not seem to be standards to judge some as failing and to open them up for control. These new ways of assessing and intervening upon persons seem to operate differently. How should we analyse them?

\section{Variation}

7 ake, for instance the question of the 'normal' human genome. Is there such a thing? In the early days of human genome project, when the term 'geneticisation' came into fashion amongst critics, it was often thought that the sequencing of the human genome would establish such a single 'normal' sequence - a composite or 'consensus genome'. It was suggested that this sequence would serve as a norm of health against which all discrepancies would be judged as morbid abnormalities (e.g. Flower and Heath 1993). A new form of molecular surveillance was often predicted that would categorise individuals as healthy or pathological on the basis of the sequences of bases on their genome, and would divide them up and administer their lives in the light of this implacable biological truth.

Cut to the present. The draft sequence of the human genome published on 11th February does not produce a single 'normal' sequence. On the contrary, it appears that there are millions of locations on the genome where individuals differ from one another by a single base - an A is substituted by a C, for example. ${ }^{2}$ The variations that comprise such SNPs - we are sure to discover more of them - do not seem to function along the axis of the normal and the pathological or the healthy and the sick. The two genomes

2 The 'public' genome identifies some 1.42 million single nucleotide polymorphisms, Craig Venter's group identify 2.1 million SNPs, very few of which - less than $1 \%-$ seem to result in variations of the proteins coded.
(DNA sequences) that each of us carry differ from one another as well as from those carried by other individuals. Every sequence identified as a 'gene' now seemed to be marked by such variation. In the human genome, to quote a recent article on pharmacogenomics "the normal is rare". ${ }^{3}$ Or, perhaps, one might say: variation is the norm. This is a variation so complex and multidimensional that it cannot easily be mapped onto the earlier ideas of genes as single entities which exist in a small number of alleles, some of which are normal, others pathological. This new molecular vision of individuality does not seem to operate in terms of the binary of normal and pathological or the mapping of a social judgement of worth onto a medical judgement of morbidity. We seem to have a geneticisation of variability without the reciprocal positing of a norm - variation without a norm.

I'd like to consider this idea by saying a bit about three areas that seem unrelated, but will help me explore the contemporary reshaping of personhood. The first is 'susceptibilities'. The second is biopsychiatry. And the third is commerce.

3 'In his 1997 book, Pharmacogenetics, Wendell W. Weber quotes from Somerset Maugham's account of his experiences as a young medical student. ... "I have always worked from the living model. I remember that once in the dissecting room when I was going over my 'part' with the demonstrator, he asked me what some nerve was and I did not know. He told me; whereupon I remonstrated, for it was in the wrong place. Nevertheless he insisted that it was the nerve I had been looking in vain for. I complained of the abnormality and he, smiling, said that in anatomy it was the normal that was uncommon. I was annoyed at the time, but the remark sank into my mind and since then it has become forced upon me that it was true of man as well as anatomy. The normal is what you find but rarely. The normal is the ideal. It is a picture that one fabricates of the average characteristics of men, and to find them all in a single man is hardly to be expected." Maugham's observation -that the normal is rare -is at the heart of the challenge and promise of pharmacogenomics.' (Norton, 2001: 180) Thanks to Oonagh Corrigan for this quote. 


\section{Susceptibilities}

I $n$ recent medico-ethical debates about the genetics and therapy of particular conditions, normativity no longer seems to be understood in terms of the self-regulation of a vital order. When the human being is viewed through a molecular gaze, in terms of sequences of bases in stretches of DNA, the vocabulary of abnormality seems to mutate. There is still a logic of absolute pathology disorders such as Huntington's arise inescapably from a specific identified set of repetitions in the base sequences in a particular gene region. But even that fatal logic is not a logic of fatalism as Carlos Novas and I have argued elsewhere (Novas \& Rose, 2000). In any event, such apparently implacable pathologies are merely the extreme point of a rather different perception. One might call this 'risk'. But that word is overworked: let us think in terms of 'susceptibility'.

This shift from implacable abnormalities to manageable susceptibilities is an element in a wider reshaping in practices for the government of persons. Gilles Deleuze has suggested that contemporary societies are no longer disciplinary, in the sense identified by Foucault - they are societies of control. Where discipline sought to fabricate individuals whose capacities and forms of conduct were indelibly and permanently inscribed into the soul - in home, school or factory today control is continuous and integral to all activities and practices of existence. We are required to be flexible, to be in continuous training, life-long learning, perpetual assessment, continual incitement to buy, to improve oneself, constant monitoring of health and never-ending risk management. A recurrent demonstration of capacity is required in order to obtain work, credit, insurance, citizenship - the active citizen must engage in a constant work of modulation, adjustment, improvement.
This is evident in the obligations to our corporeal existence. At the gross level, we know these only too well - the obligation to take care of oneself, to adjust lifestyle, diet, alcohol consumption, and the like in the light of information about health consequences, the requirement to inspect ones breasts or testes for symptoms of cancer, to have regular medical check ups, to optimise ones corporeal existence. This is not merely for oneself, but because, through the activation of this will to health, one will also perform a service for the national economy (state expenditure on health care and pensions), for the fitness and competitiveness of the labour force, and for ones family and kin. Of course, we are not all good subjects of this ethics of health - despite the risk of exclusion for employment, insurance, perhaps soon even health care itself, to say nothing of the risks of illness and early death - hence the space opened up for the professionals of health promotion.

What is added to this by the contemporary developments in the life sciences and biomedicine? Previously the assessment of risk was probabilistic - it operated in terms of one's location in a risk group by family history, body mass index, status as a man of a certain age or whatever. What is now promised is a precise calibration of one's individual, specific susceptibilities. New medical classifications of illness are framed in these terms. For example, one condition involving fronto-temporal Dementia and Parkinsonism is known as FTDP-17 because it is linked to a number of mutations in a specific region of chromosome 17. Increased susceptibility to breast cancer has been linked to the mutations known as BRCA1 and BRCA2 on chromosome 13. Researchers have tried to link variations in personality such as novelty seeking, or psychiatric disorders such as manic depression, with the synthesis or non-synthesis of particular pro- 
teins or the characteristics of particular neuronal transmitters or neural receptor sites chromosome 11 being a particular favourite. The mapping of the human genome, and the identification of SNPs will merely accelerate these processes.

We have moved, if you like, from mass production to niche marketing. Enthusiasts claim that such screening will soon be able to reveal individual 'susceptibilities' understood in terms of particular polymorphisms particular locations on a specific chromosome. This will reshape genetic counselling of partners before embarking on procreation - they will now have the option to examine the precise print-out of their genetic errors and to assess their compatibility - or to wilfully, perhaps irresponsibly, refuse. Screening of foetuses before birth in many countries is almost obligatory, especially for parents in high risk groups - now some suggest that the characteristics of the foetus, its virtues and defects, the story of the ills it will be heir to, will be readable before it has any interests to defend. Private firms, especially in the USA, are offering genetic profiling to adults on a commercial basis - a genomic version of fortune telling perhaps. And, in routine medical use, conditions are already being located to specific molecular specificities which can be identified by the screening long before they manifest themselves. Awareness that one is liable to a late onset genetic condition will spread from the few to the many.

In this sense, then, the ambit of disease, and the powers of the doctor are greatly extended to engage those who are neither phenomenologically nor experientially ill. Such persons may indeed live healthily for years, never become ill, or be injured or die in a hundred other ways. Everyone has their own susceptibilities, everyone becomes, in potential at least, asymptomatically ill and a suitable case for medical tutelage. But, before we rush too quickly to condemn geneticisation, reductionism, determinisms and the like, we need to pause. The idea of risk assessment conjures up images of certainty and calculability and hence, perhaps, a certain fatalism. But in the world of susceptibilities, the management of uncertainty is the norm - for molecular presymptomatic diagnosis gives no calculability to the 'when' or the 'how' of illness or death, nor to the manifold life decisions that must be made between the moment of diagnosis and this imagined end point. What arises in this new space of uncertainty, is not fatalism, not what Robert Proctor has termed 'enlightened impotence' (Proctor, 1995: 247), not merely anxiety, guilt, fear, stigmatisation and discrimination without hope of remedy, ${ }^{4}$ although all these are important. We also see the birth of new forms of activism - the crafting of a life and modulation of a lifestyle - in relation to oneself, one's kin, one's progeny, one's fellow sufferers - in the light of ones susceptibilities. The potential sufferer is to become skilled, prudent and active, an ally of the doctor, a proto-professional - and to take their own share of the responsibility for managing their bio-genetic selves. Those who are designated at genetic risk and their families are not passive elements in the search for remedies. Such persons are increasingly demanding control over the practices linked to their own health, seeking multiple forms of expert and non-expert advice in devising their life strategies, and asking of medics that they act as the servants and not the masters of this process. Persons identified as susceptible to a particular condition have an investment in scientists fulfilling their promises and discovering the basis of, and the cure or treatment for, genetic conditions.

\footnotetext{
4 These are emphasised in particular in the writings of Dorothy Nelkin, e.g. Nelkin and Tancredi, 1989.
} 
Contemporary biomedicine, like its predecessors, is one of the key sites for the fabrication of the contemporary self - free yet responsible, enterprising, prudent, encouraging the conduct of life in a calculative manner by acts of choice with an eye to the future and to increasing their well-being. Genetic personhood is one of 'genetic responsibility'. And genetic responsibility induces new forms of biological community - what Paul Rabinow has termed 'biosociality' (Novas \& Rose, 2000, Rose, in press). Consider, for example, the Genetic Alliance which, since the mid-1980s has sought to foster " a dynamic coalition of consumers and professionals to promote the interests of children, adults and families living with genetic conditions" bringing together almost 300 support groups with consumers and health care professionals, "creating partnership solutions to common concerns about access and availability of quality genetics services." ${ }^{.5}$ Those with similar genetic susceptibilities, or their families, gather into support groups, run websites and email discussion lists, raise funds for medical research, engage their own medical experts, and develop and disseminate practices for crafting a life 'at risk' and a new ethics of the susceptible.

This is not to deny that bio-genetic personhood is also linked to new forms of exclusion. Most critics fear a new genetic division between normality and pathology, now inscribed implacably in ones genes. Absolute otherness remains. But elsewhere, we seem to have moved beyond the binary opposition between a normal body and one destined, by its genes, to abnormality. The vocabulary of risk assessment and risk management illuminates these new relations between control by inclusion and control by exclusion. Risk thinking - say in the case of psychiatry entails attempts at the constant monitoring, su-

5 http://www.geneticalliance.org/allianceinfo.html pervision and management thought necessary to maintain 'risky' or 'at risk' individuals in the circuits of everyday life. But it also reveals what one might think of as the 'three faces of risk'. The first face is turned to those whom professionals judge to be permanently unable to manage their risk: the response is incapacitation. This is notably the case in strategies for the preventive detention of incorrigible individuals such as sexual predators, paedophiles and the intractably anti-social. The new biology plays a part here, as biological criminologists and forensic psychiatrists search for methods to discover the biological underpinnings of such conduct. For some at least, the objectivity apparently promised by the new molecular biology and genetics is called on to legitimate the detention of an individual, not on the grounds of what they have done - deviant conduct - but on the grounds of who they are - their biogenetic personhood. This would enable the experts to meet political demand that they should be able to identify members of this new class of 'monsters', before they commit their offences, or after they serve their allotted term of imprisonment. For these monsters, a residual biological determinism seems strategically essential.

The second face of risk is turned to those who are not monsters, but merely troublesome: the drug addicts, alcoholics, repeat petty offenders, those judged chronically mentally ill. For these individuals, one sees the developments of a new penal-welfare complex, a kind of cycling between the street, the shelter or the half way house into the prison, mental hospital or secure unit. Secure provision here functions, in the last resort, as a form of internal exile to sequester those who appear threatening or merely disturbing to public order - as in the idea of zero tolerance policing. The strategy is one of long term risk management. Ideally, the risk posed by such troublesome individuals 
would be managed without incarceration, often by combining professional surveillance with long term administration of psychiatric drugs. But where the experts consider that the individual is unable to manage their riskiness prudently - to keep taking their medication in order to control their symptoms, or to modify their behaviour by abstaining from drugs, alcohol or petty crime - they are to be returned to hospital or prison where further risk reduction measures may be put in place - sometimes involving cognitive forms of therapy to teach the skills of behavioural control and the 'insight' necessary to keep taking the tablets. Here too the new biomedicine feels it has something to offer. On the one hand, there are the new non-traditional neuroleptic drugs with an apparently lower side effect profile to reduce the chances of 'non-compliance' with the maintenance therapy. And, on the other, there are a multitude of claims to have discovered new 'smart drugs' that will target the neurochemical bases of these troublesome conditions, for example drugs that will target the neuronal receptors involved in the pleasure effects of alcohol or illegal drugs, and reduce the 'desire' of the addict for their substance of abuse.

There is a third face of risk, in which the birth of bio-genetic personhood - of the person with biological susceptibilities - is reorganising less dramatic circuits of exclusion. I have already mentioned fears of genetic discrimination, where insurance eligibility, employment and the like, once linked at a rather gross level to family history of health and illness, is now increasing tending to be molecularised - with arguments about the legitimacy of genetic screening and the like. I have argued elsewhere that it is somewhat unlikely that the worst case scenarios of the critics will come about (Novas \& Rose, 2000). As all diseases come to be seen as having a genetic basis, and all such bases come to be seen as polygenetic matters of susceptibility, such a binary will be impossible to maintain. As we all become re-configured as bio-genetic persons, to exclude all with susceptibilities for illness from insurance or employment would, indeed, be to exclude all. The more likely outcome is not so much exclusion but modulation. This would be the requirement that, if we are to be employed, receive insurance or whatever, we continually monitor our susceptibilities in the light of all that might provoke them. And that we adjust our forms of life, activities, insurance cover, financial planning and the like in the light of them. We would be obliged to sculpt our lives in terms of our own particular genetic and biological individuality. And maybe these will soon seem no more strange or reductionist than what have become common sense attributes of our somatic existence - height, weight, body shape or tastes.

\section{Bio-psychiatry}

M

y own work recently has focussed on a different part of the biomedical field - the rise of biological psychiatry - biological explanations and treatments of mental ill health. One might term this 'the birth of neurochemical self'. And if one looks at psychiatry, and at its role in the government of this new neurochemical self, this argument for variability without norms seems hard to sustain.

Of course, psychiatry has always been plagued by the problem of its norms. In the nineteenth century, clinical medicine as we know it began when the gaze of the doctor plunged into the interior of the body, visualising the organic locations and lesions of the symptoms that could be discerned on its surface. From that moment onwards, to diagnose an illness was to interpret those symptoms in terms of the organic malfunctions that were their cause. Of course, the mad 
person was one who came to notice, first of all, because of a breach of the conventions of order, conscience, civility, and norms of personhood. The new profession of psychiatry attempted to ground this violation of norms in a pathology that could be discovered in very make-up of the mad person. But despite its conviction that it was dealing with a disease of the brain, psychiatry failed to make madness visible within this deep interior of the body. At first, the doctors of the mad used their educated vision to make their diagnoses, and focussed upon the surface of the body - posture, gaze, the colour of the skin of the melancholic, the gestures of the maniac, the movements of the hysteric. In the twentieth century, the eye gave way to the ear - it was the voice of the patient, what was said, that was to be interpreted, and that provided the royal road to a diagnosis. Mental ill health now seemed undeniably to be a psychological matter.

In the twentieth century, of course, almost all the criticisms of psychiatry stemmed from its apparent inability to find an objective correlate for its judgements. When asked "how do you know that this person is suffering from a mental illness", psychiatrists could only claim their expertise in interpretation of the pathologies of conduct in question, and the evidence of the diagnostic interview. This problem arose in relation to criminal responsibility in the courts of law, where psychiatrists often found their own forms of reasoning about madness were unable to meet legal criteria of evidence and proof. It arose in cultural disputes, where critics argued that, in the absence of objective correlates of its judgements, psychiatry merely medicalised deviance and upheld the norms of a patriarchal social order. It arose in political controversies, where Western psychiatrists accused their brethren in the Soviet Union and elsewhere of political abuse of psychiatric judgements. Hence Georges Can- guilhem's acerbic reflections in 1956, that the psy sciences stood between two paths the uphill path led to the Pantheon where the wise and the great were commemorated, the downhill path led to the police station (Canguilheim, 1980).

Psychiatry today seems to stand at this same crossroad. Down the one road, it seems to be incorporating more and more conditions that appear to be simply violations of prevailing standards of acceptable personhood. One only has to consider a few of the many new psychiatric categories that have been created in the last twenty years - each of which now forms the basis of a mini-psychiatric specialism. We have post traumatic shock disorder, attention deficit hyperactivity disorder, body dysphoric disorder, panic disorder, social phobia. And, in addition, there is that pandemic of 'minor' troubles that now receive psychiatric attention even if only in the form of medication - from anxiety to sub-clinical depression. And there are all the disorders of sleep, appetite, mood and will in children that are now termed depression. Is this not the downhill path that, in the end, still lead to the police station?

But, at the very same time, psychiatry, in its new biological guise, claims to have conquered that steep hill to truth. The previously inaccessible bodily seat of the mind now seems to be opened out and spread before the psychiatric gaze. Brain imaging shows the differences in the regions that light up in the 'normal' and 'schizophrenic' brain, or fail to light up in the brain of a depressed person. Molecular neuroscience anatomises the neurones, the receptors, the neurotransmitters, the cell membranes and ion channels, and allocates a specific pattern of functioning to each normal or abnormal mental state. Genetics seek the gene sequences that correlate with each diagnostic category - to identify the precise functions of the variations they discover - a deficiency in the metabo- 
lism of a neurotransmitter, in the receptors, in a particular channel. Pharmaceutical companies fund most of this research: they compete to fabricate a chemical corrective to this molecular error - a serotonin selective reuptake inhibitor, to take the most famous case of Prozac.

Thus psychiatry claims to have overcome, at last, the Cartesian dualism of body and soul. In its new 'neurochemical' account of personhood, it no longer distinguishes between organic and functional disorders, with only the former being thought of as somatic. It no longer concerns itself with the mind or the psyche. Mind is simply what the body, what the brain, does. And mental pathology is simply the behavioural consequence of an identifiable, and potentially correctable, error or anomaly in some aspect of the brain - in its neurotransmitters, receptors and the like.

What is this new psychiatric self? Let me take an example at random from a recent paper, concerned with a subtype of schizophrenia that is associated with aggressive symptoms. The paper argues that this condition is linked to a variation in a single base in the gene for an enzyme called catechol- $O$-methyl-transferase (COMT). This gene has been located to chromosome 22q11 and sequenced. The variation is a transition from $\mathrm{G}$ (guanine) to A (adenine) in the DNA sequence. It leads to valine being substituted for methionine in codon 158 of the enzyme. This enzyme has been shown to be involved in the breakdown of certain neurotransmitters. So an error in the make up of the enzyme will disrupt this breakdown process, leading to more or less of the neurotransmitter in question being present in the synapses in particular regions of the brain. And other research has shown that violent behaviour can be linked to anomalies in the synthesis or breakdown of these neurotransmitters (Strous et.al., 1997). Here we can see the paradigmatic 'style of thought' of biological psychiatry. It proceeds from symptoms to the brain to neurotransmitters to gene sequences. A simple reversal of this chain of detection appears to generate a chain of causality.

The initial diagnosis seems normative enough. The symptoms only appear as such in relation to conventional cultural standards of personhood, conduct and public order. And once more, a reading from the social to the vital seems to take place, as these are interpreted as consequential upon a defective biological state. But at the biological level we do not seem to have a violation of a norm - the norm of an organic and self-regulating system disturbed by illness. What we seem to have here is an error, simply a mistake in a bit of the machinery of the brain and its neurochemistry. And this is an error that is potentially correctable - for if it is merely a question of a chemical malfunction, we can, potentially, fabricate an artificial alternative, a drug. Not to normalise the person, but to correct an error. So even in these extraordinarily simplistic versions of the genetic and neurochemical basis of mental ill health, the logic of the norm seems to have mutated.

In fact, the most hard-headed advocates of behavioural genomics seldom adopt this simplistic analysis that links one gene to one condition. Most now argue that, in the biology and genetics on mental illness, we are not dealing with single genes and unitary pathologies but with variations in multiple loci in multiple gene systems resulting in continuous distributions of phenotypes and susceptibilities to particular disorders in specific environments (McGuffin et. al, 2001). In this complex set of relays and relations, the consequences of a genetic and neurochemical account of mental illness are not fatalism. On the contrary, the writers here draw a different lesson. Genetic diagnosis will help individuals take responsibility for the management of their condition, for the control of 
their susceptibilities, for the use of all possible forms of pharmacological correction of the underlying error or deficiency, thus enabling the susceptible individual to maintain themselves in the circuits of inclusion. The chain of reasoning characteristic of biological psychiatry operates to underpin a dream of individually tailored pharmaceutical intervention at the molecular level to correct a susceptibility. This is not so much normalisation as correction.

But surely, psychiatry still treads the downhill path to the police station. Of course it does - we know that many individuals are being confined and treated against their will. But many do not go that distance. Psychiatry is not confined to those gross violations of institutional norms leading to a loss of citizenship and normalisation under compulsion. Increasingly, psychiatric categories relate to everyday failures of integration of the individual into those circuits of consumption and autonomous self actualisation. And psychiatric treatments - drugs and cognitive therapies being the predominant forms of treatment in the UK and USA these days - seek to maintain the affected individual within those circuits or restore them to them - to reactivate the capacity to live a normal life, to craft a life for oneself.

One indicator of this is the blurring of the distinction that psychiatry used to try to maintain between states and traits. The state of illness requires a definite change of functioning in the patient at a definite moment in time. You were well, you are now ill, you may get well again. Traits are persistent underlying features of the individual. So if you were a cheery soul and now are having trouble sleeping, eating, getting fun out of life, you may have a depressive illness. If you are a generally miserable kind of person, well that's your personality, not an illness- persistent melancholics are not suffering from a depressive illness but from a depressive per- sonality. Psychiatry treats illnesses, it has long been claimed, not states - hence it cannot treat anti-social personality disorder psychopathy - because that is not an illness. But now this distinction is hard to maintain. Take neuroses, for example. The category has actually disappeared from DSM IV - the diagnostic bible of the American Psychiatric Association, as have associated notions, such as reactive or neurotic depression. If we take neurotic depression, well a form of depression less severe than major affective disorder is now termed 'dysthemic disorder' and it is said to be often associated with a lowness of mood that begins early in life ("I've always been this way"). Hence it merges imperceptibly with the trait diagnosis of personality disorder. And now, biological and genetic correlates of these neurotic conditions may be found. So if these conditions can be corrected with drugs, and it is claimed they can, what has become of the distinction between treatment of an illness and modification of a personality trait? It is hard to maintain. Traits must be treated as well as states, because traits are, once more, susceptibilities. The door to psychiatric treatment of personality to reshaping and enhancement of neurochemical personhood - is already wide open.

Psychiatry, then, still has a key role in governing the self. This is not merely to return the individual to a fixed norm of civilised conduct as housewife or worker - a once off programme of normalisation. Rather, its ambition is the restoration, and continual, long-term maintenance of the free, autonomous, individual obliged to choose and to take responsibility for his or her life as if it were an outcome of acts of choice. But further, biological psychiatry seems to be offering the possibility of the calculated modification and augmentation of personhood itself. In its new neurochemical and psychopharmacological guise, it is contributing to the idea of the flexible, manipulable self - 
manipulable not only in the service of projects of normalisation, but manipulable by the person him or herself in the service of enhancement of capacities. Psychiatry, that is to say, is deeply implicated in the continual process of modulation of capacities that has become the life's work of each active citizen.

\section{Capitalisation}

$\mathrm{F}$ inally, let me say a little about the most obvious feature that underpins all that I have said so far about what is happening today - the enormous capitalisation of the life sciences and biotechnology - the capitalisation of life itself.

First, consider the capitalisation of the treatment capacities of medicine, in particular via the pharmaceutical companies, whose shareholder value is utterly dependent upon the production, marketing and medical takeup of a few blockbuster drugs. The top 5 drugs prescribed in the USA in 1999 being Premarin, a conjugated oestrogen for the treatment of symptoms of the menopause hormone replacement therapy; Levothyroxine for the treatment of thyroid deficiency - a condition characterised by general lethargy and lack of activity; Lipitor, for the treatment of hyperlipdemia - high levels of blood lipids thought to predispose to heart attack; and Omeprazole for the treatment of peptic disorders and ulcers. Prozac was tenth, but its close cousin Zoloft was 11th and Paxil was 15 th - these are drugs that have vastly reshaped and extended our beliefs as to what is treatable depression; Viagra, the anti-impotence drug which claims to extend and enhance sexual potency only came in at 47th, but this was 1999. The power to reshape life - the words 'illness' and 'cure' seem inadequate here - seems to extend way beyond what we previously understood as illness. These top selling drugs are those that treat 'life conditions' and are thus prescribed 'chronically' rather than 'acutely'. Biomedicine has already rewritten the norms of reproduction - its timetables, its kinship relations. Hormone replacement treatment is already rewriting the norms of female ageing. Drugs for 'panic disorder' such as Alazopram are rewriting the norms of social interaction. So the capitalisation of the power to treat intensifies the redefinition of that which is amenable to correction or modification. This is not simply blurring the borders between normality and pathology, or widening the net of pathology. It is mobilising ideals of hypernormativity - we see a kind of co-production of the drug and the niche market for it, and in the process, the emergence of a much more general market for drugs that will reshape our capacities to live.

Second, we have a capitalisation of truth itself. Vast sums of money, huge research teams, enormously expensive equipment are now required to produce biological and biomedical truth. The idea of a distinction between pure science and application can no longer be maintained. We can no longer believe that things are first discovered in the pure world of knowledge and then set to work in the mundane word of existence and commerce. The laboratory is itself a factory. Bioscience knows by creating, by transforming, by intervening. Increasingly it knows by manufacturing - creating all those lifelike things that never existed before - from immortal cell lines, to cloned DNA sequences within bacteria, to mice with artificially inserted or deactivated genes. Its priorities, its funding, its machinery and its processes are industrialised. The pharmaceutical industry has been central to research on neurochemistry, the biotech industry to research on cloning, genetech firms to the sequencing of the human genome. This is a genuinely new field and we do not yet really grasp its operations. These new alliances between aspira- 
tions to health, to profit, to professional advancement, to discovery, to human improvement are reshaping the very idea and the very reality of what it is to be human.

Third there is the capitalisation of the body, or rather of organs, tissues and cells. The human genome has become a happy hunting ground for venture capitalists and gene-tech companies. The line between discoveries and inventions is hard to maintain, as discoveries are transformed into property through patent law and the devices of intellectual property. There is a flourishing trade in organs, body parts and cells, for transplantation, research and for pharmaceutical manufacture. There is a growing industry of DNA profiling - for health, insurance and police, and also for individual paternity suits. No doubt there is much more. This is one aspect of the rise of what Catherine Waldby has termed 'biovalue': the new imperative is to produce a kind of "surplus value of vitality and instrumental knowledge" from the human body itself (Waldby, 2000: 19). Contemporary biotechnology, that is to say, does not only manage vitality. It does not only seek to combat things which would threaten that vitality. It is geared to the production of knowledges and techniques that can actually enhance vitality. It seeks to instrumentalise these possibilities, integrating them in economies of health, of lifestyle, of productivity. The life science and biomedicine are now attuned to the maximisation of biovalue. In this context, those aspects of life that were previously devalued - deviations from the norm to be controlled - now seem to be precisely opportunities for the creation of value - to discover new genetic and neurochemical errors is to open new markets and new customers for new products.

One of the most fundamental consequences of this capitalisation is that truth is no longer a sufficient value to legitimate and drive the biosciences. As Paul Rabinow has animate the financial and institutional conditions - the venture capitalists, patent lawyers, pharmaceutical companies - upon which the biosciences depend today - depend in an absolute sense in that these are the conditions of the knowledges they generate. Health, not truth, has become the central value - a value which is both moral and commercial. Where Foucault analysed biopolitics, we now must analyse bio-economics, in which human capital is to be understood in a rather literal sense - in terms of the new linkages between the politics and economics of life itself.

\section{Concluding thoughts}

$\mathrm{I}$ $n$ the West, at least, it seems that the sacred is no longer simply something above and beyond life, no longer the realm of spirit and salvation. The body itself has become sacred. Salvation has become linked to our existence as corporeal, somatic individuals. And health has come to be seen as our principal ethical value. We have here a whole 'economy of hope'. This economy thrives on perceptions of scarcity - funding for public health care seems always inadequate, institutions discriminate on grounds of health, illness is a financial burden, providing for treatment a constant worry, loss of health a constant threat. It seems there is never enough health. In an economy of scarcity, hope - for cures, for fitness, for longevity, for procreation - has become intrinsic to a whole set of economic relations -the creation of markets by companies, the activities of scientists, the work of the mass media, the actions of patients, potential patients, support groups and families in fund raising and the like. In the apt term proposed by Carlos Novas, this is "the political economy of hope" (Novas, In Press). 
The ethical issues raised by these developments are profound. But I do not think they can be resolved by repeating the comforting slogans of informed consent, the dignity of the individual, the best interests of the child or 'do no harm'. For it is our very ethical presuppositions that are at stake here, our conceptions of personhood, of the distinctions between fate and choice, nature and artificiality. And these presuppositions are being reshaped at the micro-level, through the thousands of everyday decisions that are being taken by researchers, investors, managers of pharmaceutical companies, doctors and patients. It is there, in the actual field of biomedical research and practice, that the truly significant ethical work is being undertaken - on who we are, what we must do and what we can hope for.

What, finally, of norms. I have suggested that we have escaped, at least partially, the era of the normal and the pathological, with a causality burdened by the shadows of infamy, guilt and blame. Ours is, perhaps, a time of errors, of anomalies, of mistakes, which carry no such moral loads. Cancer no longer is 'a cancer at the heart of society' but a susceptibility written in a particular sequence of bases in a gene (Sontag, 1979). For normalisation, read correction. Correction blurs the distinction between treatment, adjustment and enhancement. Of course, these judgements still carry a moral burden. But I do not think this is the same as it was when norms were inscribed in the very vital essence of each human being. And I do not think that control still operates by overlaying the normal the average, the virtuous, the ideal and the socially adapted. This it why I think - though I am far from certain, that we are no longer governed by the logic of the norm.

\section{References}

Canguilhem, G. (1978 [1943]). On the Normal and the Pathological. Dordrecht: Reidel.

Canguilhem, G. (1980). What is psychology? Lecture delivered in the College philosophique on 18 December 1956. Ideology \& Consciousness 7: 37-50.

Flower, M. \& Heath, D. (1993). Micro-anatamo politics: mapping the human genome project. Culture, Medicine and Psychiatry, 17: 27-41.

McGuffin, P. Riley, B. \& Plomin, R. (2001). Toward behavioral genomics, Science, 16 Feb 2001: 1232-49.

Nelkin, D. \& Tancredi, L. R. (1989). Dangerous diagnostics: the social power of biological information. New York: Basic Books.

Norton, R. M. (2001). Clinical pharmacogenomics: applications in pharmaceutical R\&D. Drug Discovery Today, 6(4).

Novas, C. (In Press). The political economy of hope. Manuscript.

Novas, C. \& Rose, N. (2000). Genetic risk and the birth of the somatic individual. Economy and Society 29:4, 485-513.

Proctor, R. (1995). Cancer Wars, New York: Basic Books.

Rabinow, P. (1999). French DNA: Trouble in Purgatory, Chicago, Il: University of Chicago Press.

Rose, N. (In Press). The politics of life itself. Under review in Theory, Culture and Society.

Sontag, S. (1979). Illness as Metaphor. London: Allen Lane.

Strous et al. (1997). Analysis of a functional catechol-O-methyltransferase gene polymorphism in schizophrenia: evidence for association with aggressive and antisocial behavior. Psychiatry Research 69: 71-77.

Waldby, C. (2000). The Visible Human Project. London: Routledge. 